Como citar este artigo: Conde, R., \& Teixeira, S. (2018). Delinquência juvenil em portugal: estudo qualitativo das histórias de vida de jovens reclusos. Revista Psicologia, Diversidade e Saúde, 7(1) 47-59. doi: 10.17267/2317-3394rpds.v7i1.1844

\title{
Delinquência juvenil em Portugal: estudo qualitativo das histórias de vida de jovens reclusos
}

\author{
Juvenile delinquency in Portugal: qualitative study of the \\ life stories of young prisoners
}

\author{
Rita Conde', Silvana Teixeira² \\ 'Faculdade de Psicologia, Educação e Desporto; Universidade Lusófona do Porto. Porto, Portugal. ana.dias@ulp.pt \\ ${ }^{2}$ Universidade Lusófona do Porto. Porto, Portugal.sdvtt@hotmail.com
}

Resumo | A investigação sobre a delinquência juvenil ao nível internacional caracteriza-se maioritariamente por estudos quantitativos, procurando medir o fenómeno ao nível da prevalência, identificar preditores e fatores de risco. Os estudos qualitativos que procurem compreender as experiências de vida dos jovens delinquentes são em menor número e, especificamente em Portugal, são ainda mais escassos. O presente estudo procura colmatar esta lacuna, procurando compreender as trajetórias de vida e a significação das experiências dos jovens delinquentes. Assim, analisam-se as histórias de vida de 9 jovens delinquentes que praticaram crimes e que estão recluídos num centro educativo. $O$ estudo procura identificar as áreas e experiências de vida mais relevantes dos jovens e de que forma as significam e vivenciam. Utilizou-se a análise temática para a análise dos dados. Da análise resultou a identificação de cinco temas centrais: família, grupo de pares, comportamentos delinquentes, percurso escolar e institucionalização/reclusão. Os resultados indicam que os comportamentos antissociais/delinquentes são, de facto, um dos temas predominantes no discurso, traduzindo-se na maior parte dos casos em experiências partilhadas com os pares, nomeadamente o consumo de substâncias, a prática de crimes contra a propriedade e as ofensas à integridade física. Os remorsos e os sentimentos de culpa surgem associados à descrição dos comportamentos criminais. Conclui-se que, ao nível da prevenção, a componente relacional deve ser alvo de atenção, nomeadamente as relações familiares e a relação com os pares. A componente escolar assume também importância, verificando-se a escassez de experiências positivas e de sucesso escolar.

Palavras-chave: Delinquência Juvenil; Crime; Prisioneiros; Análise qualitativa.

\begin{abstract}
Research on juvenile delinquency at the international level is mainly characterized by quantitative studies, trying to measure the phenomenon in terms of prevalence, to identify predictors and risk factors. Qualitative studies that attempt to understand the life experiences of young offenders are fewer and, specifically in Portugal, are even more scarce. The present study tries to fill this gap, trying to understand the life trajectories and the meaning of the experiences of the young delinquents. Thus, the life histories of nine young offenders who have committed crimes and are being detained in an educational center are analyzed. The study aims to identify the most relevant areas and life experiences of young offenders and how they are meant and experienced. Thematic analysis was used to analyze the data. The analysis resulted in the identification of five central themes: family, peer group, delinquent behaviors, school path and institutionalization/prison. The results indicate that antisocial/delinquent behavior is, in fact, one of the predominant themes in discourse, which is revealed in most cases in experiences shared with peers, such as substance use, property crimes and offenses to physical integrity. Regrets and feelings of guilt arise associated with the description of criminal behavior. It is concluded that, at the level of prevention, the relational component should be the object of attention, namely the family relations and the relationship with the peers. The school component is also important, because there is a lack of positive experiences and success in school.
\end{abstract}

Keywords: Juvenile Delinquency; Crime; Prisoners; Qualitative analysis. 


\section{Introdução}

A delinquência juvenil tem sido estudada, fundamentalmente, através da metodologia quantitativa. Sendo a metodologia quantitativa na sua essência quantificação e dado que o significado atribuído às experiências delitivas não é passível de ser mensurado, verifica-se a necessidade de se desenvolver investigação qualitativa sobre o fenómeno.

A literatura indica que o fenómeno tem na sua génese uma enorme variabilidade de factores, experiências e condições de vida que diferem na forma como são vivenciadas por cada jovem em conflito com a lei (Nardi \& Dell'Aglio, 2010). Os jovens delinquentes são alvo de investigação, mas os estudos que considerem a sua própria "fala" são raros (Estevam, 2011; Janay, Sander, Sharkey, Olivarri, Tanigawa, \& Mauseth, 2010).

A existência de fatores de risco e a ação moderadora ou não dos fatores de proteção, por si só, não explica a ocorrência da delinquência, tornandose essencial entender 0 contexto em que esses fatores se podem manifestar (Nardi \& Dell'Aglio, 2010). Face ao exposto, verifica-se a necessidade de estudos qualitativos sobre a delinquência juvenil que procurem contextualizar os comportamentos delinquentes no seu percurso de vida, compreender a forma como jovens os experienciam e significam, ou seja, dar voz aos próprios jovens.

\section{Definição e conceptualização teórica da delinquência juvenil}

A definição de "delinquência juvenil" não é consensual na literatura, sendo os termos delinquência e comportamento antissocial frequentemente utilizados como sinónimos. O termo comportamento antissocial é mais abrangente, referindo-se a atos transgressivos ou a violações de normas ou de expectativas sociais que são considerados inapropriados porque causam danos nos outros e/ou à sociedade (Guimarães, 2012). O termo delinquência é uma designação jurídica, referindo-se à transgressão das leis e que implica uma consequência penal ou a intervenção judicial/institucional (Nardi \& Dell'Aglio, 2010).

No entanto, apesar desta distinção, verificase que não há uma "operacionalização" comum entre os investigadores do termo "delinquência juvenil", havendo autores que consideram apenas os comportamentos que constituem crime (Burfeind \& Bartusch, 2011) e outros que integram todos os comportamentos e/ou violações às normas e expectativas (Kagan, 2004).

Porque a transgressão das normas e expectativas sociais podem incluir uma grande variabilidade de comportamentos que, não necessariamente, criminais, no presente estudo adoptar-se-á a definição mais restrita de Burfeind e Bartusch (2011): considera-se delinquência juvenil as acções ou comportamentos que violam a lei e que são cometidos por alguém que seja menor de idade (menores de 18 anos).

É de destacar ainda que na literatura existem várias teorias e modelos que procuram explicar o fenómeno da delinquência juvenil, desde os que enfatizam as características individuais, os fatores familiares, aspectos socioculturais, até aos desenvolvimentais e biopsicossociais (Burfeind \& Bartusch, 2011).

\section{Delinquência juvenil: como tem sido estudada}

A delinquência juvenil é uma problemática existente a nível mundial, sendo alvo de estudos de prevalência e incidência - os valores diferem em função da sua definição operacionalização e instrumentos utilizados mas, globalmente, são preocupantes. Em Portugal, as estatísticas oficiais do Relatório Anual de Segurança Interna (RASI, 2016) indicam flutuações da delinquência nos últimos anos, verificando-se um pico em 2010. Todavia, desde 2014 que se tem verificado um decréscimo de $-22,7 \%$ mas, contrariamente, as participações de atos ilícitos cometidos em ambiente escolar feitas ao "Programa Escola Segura" têm aumentado (RASI, 2016; Vieira, 2014).

O primeiro estudo nacional realizado no âmbito do International Self-Report Delinquency Study (ISRD) em 1994 por Gersão e Lisboa com 1000 jovens residentes em Portugal Continental de ambos os sexos, entre os 14 e os 21 anos, revelou uma prevalência total de delinquência de $57.2 \%$ (Braga \& Gonçalves, 2013). O estudo de Braga e Gonçalves (2013) com uma amostra de conveniência de 676 participantes, 495 do género feminino e 181 do género masculino, com idades 
compreendidas entre os 12 e os 24 anos, revelou que atos de agressividade verbal foram admitidos por $53.1 \%$ dos participantes, agressão física por $18.9 \%$ e comportamentos de violência por $3.7 \%$. O estudo indica que há um decréscimo acentuado da prevalência à medida que a gravidade dos atos aumenta, como é o caso do roubo e a violação/ abuso sexual (que não ultrapassou os $0.5 \%$ ).

Ao nível internacional, destacam-se também vários estudos que procuraram identificar preditores e fatores de risco associados à delinquência (sobretudo relacionados com a família e a comunidade, mas também com a "personalidade"), assim como a ação moderadora ou não dos fatores de proteção (Morizot \& Kazemian, 2015).

Ao nível dos fatores de risco, os estudos apontam a ausência ou défice nos vínculos sociais e/ou familiares, a violência doméstica, a violência na comunidade, a falta de suporte familiar e social, grupos de pares desviantes, bem como são referidas também características pessoais, tais como como a falta de empatia e o fraco controlo emocional (Burfeind \& Bartusch, 2011 ; López, Pérez, Ochoa, \& Ruiz, 2008; Thijs, Dijk, Stoof, \& Notten, 2015).

No que se refere aos fatores de proteção, também estes se centram na família, na comunidade e nos indivíduos. Ao nível das características pessoais identificam a autonomia, autoestima e inteligência; ao nível familiar destacam a coesão familiar (e.g.: ausência de conflitos e negligência e existência de afeto positivo); e ao nível da comunidade, são referidos os recursos institucionais e o suporte social. O suporte social na família e na comunidade potenciam a integração dos jovens e a criação de oportunidades de desenvolvimento de habilidades pró-sociais (Agan, Costin, Deutz, Edelsbrunner, Zális, \& Franken, 2015; Burfeind \& Bartusch, 2011).

No entanto, a identificação de fatores de risco não explica por si só a prática de atos criminais, até porque $o$ impacto que estes atos têm na trajetória dos jovens depende da forma como são vivenciados e significados. Esta componente experiencial e da significação só é possível ser analisada através de metodologias qualitativas (Estevam, 2011).
Ao nível internacional, apesar de em menor número, já começam a surgir alguns estudos qualitativos sobre a delinquência juvenil (e.g., Boakye, 2012; Donges, 2015; Sander et al., 2010). São de destacar o estudo de Sander e colaboradores (2010) que procura analisar as experiências interpessoais e escolares desde a perspectiva dos jovens delinquentes e das suas famílias, bem como o estudo de Donges (2015) que foca também as experiências escolares dos jovens. É ainda de realçar o estudo de Boakye (2012) no Ghana, que procurou identificar as circunstâncias que levaram os adolescentes a envolver-se em comportamentos delinquentes, entrevistando seis jovens delinquentes. Identificou como circunstâncias aspectos relacionados como a religiosidade/moral, a associação com pares desviantes, o consumo de substâncias, o funcionamento da família nuclear, - suporte inadequado da família alargada e o desinteresse pela escola.

Em Portugal, grande parte dos estudos realizados são quantitativos, focados na identificação dos comportamentos criminais e nas características sociodemográficas associadas. As diferentes agências tentam também aferir a delinquência juvenil através das estatísticas oficiais, das ocorrências relatadas às autoridades, das medidas socioeducativas aplicadas ou dos casos remetidos aos tribunais. Por seu turno, os estudos qualitativos são mais escassos, procurando contextualizar os comportamentos delinquentes e analisar a significação atribuída às experiências delinquentes desde o ponto de vista dos jovens e não do sistema.

Destacam-se os estudos de Duarte (2012) e de Carvalho e Duarte (2013). O primeiro incide na delinquência juvenil feminina, através da análise de 27 processos e 19 entrevistas individuais com jovens internadas em Centros Educativos a executar medidas não institucionais sob acompanhamento das Equipas Tutelares Educativas da área da Grande Lisboa. O segundo foi desenvolvido com crianças e jovens acerca dos riscos, violências e delinquências em Portugal, concluindo que os sentimentos e significados atribuídos às experiências transgressivas andavam em torno de histórias de abandono e de várias privações em idades muito precoces. 
É de destacar também o estudo misto, que combina metodologias quantitativas e qualitativas, de Simões, Matos e Batista-Foguet (2008) que procurou identificar fatores de risco e fatores protetores. Os resultados indicam o uso de substâncias como principal fator de risco e as experiências positivas na escola como um forte factor protetor.

Assim, dada a escassez de estudos qualitativos em Portugal e não se identificando nenhum estudo qualitativo que procure compreender as experiências ao longo da vida dos jovens delinquentes, consideramos que seria pertinente analisar as histórias e trajetórias de vida dos que se encontram institucionalizados pela prática de crime, no sentido de contextualizar a delinquência desde - ponto de vista de quem a experienciou e/ou experiencia. A primeira versão do presente trabalho foi apresentada no $6 .^{\circ}$ Congresso lbero-Americano em Investigação Qualitativa e no $2 .^{\circ}$ Simposium Internacional em Investigação Qualitativa (Conde \& Teixeira, 2017).

\section{Método}

\section{Objectivos e questões de investigação}

O presente estudo pretende explorar a trajetória de vida dos jovens institucionalizados, identificar os temas e experiências centrais na sua história de vida, compreender o significado atribuído às suas experiências e de que forma estas podem constranger $\circ$ modo como se percepcionam a si próprios e como se projetam no futuro. Mais detalhadamente, a análise será orientada pelas seguintes questões:

1. Quais são os temas e experiências centrais que surgem na sua história de vida? Como são significados esses temas e/ou experiências?

2. A delinquência ou os comportamentos antissociais é um tema que surge na sua história de vida? Se sim, que tipos de comportamentos delinquentes são relatados? De que forma? Como os significam?
3. Que experiências ou situações são consideradas, implícita ou explicitamente, na forma como se percepcionam a si próprios e ao seu percurso de vida (passado, presente e futuro)?

\section{Participantes}

O estudo incluiu 9 participantes do sexo masculino selecionados de acordo com os seguintes critérios de inclusão: (i) Jovens privados da sua liberdade em centros educativos, sob regime fechado; (ii) que praticaram crimes contra as pessoas e/ou crimes contra a propriedade; (iii) que possuam capacidades cognitivas básicas, no sentido de poderem compreender as questões e elaborar uma resposta; (iv) que não tenham sido alvo de intervenção psicoterapêutica; e ( $v$ ) Sem sintomas ativos de consumo de substâncias.

É de referir que os critérios de inclusão foram apresentados à Direcção do Centro educativo que procedeu a uma primeira selecção dos potenciais jovens. Seguidamente, após autorização, confirmouse na ficha médica os dados referentes à défices cognitivos e historial de intervenções terapêuticas.

As idades dos participantes situam-se entre os $16 \mathrm{e}$ os 18 anos $(M=18)$, sendo sete de raça caucasiana e dois de raça negra. Dos nove participantes, cinco possuem histórico de institucionalização na infância, seis cometeram cumulativamente crimes contra as pessoas e contra a propriedade e três cometeram somente crimes contra a propriedade. A maioria dos participantes mantém contacto com a família, à exceção de dois jovens.

\section{Instrumento}

Utilizou-se a Entrevista sobre a História de Vida para Jovens (Conde \&, Paiva 2014) adaptada do guião da entrevista de McAdams (2008). A entrevista foi administrada individualmente, tendose pedido a cada participante que relatasse a sua história de vida, abrangendo todos os tópicos do guião (resumo das principais fases da vida, acontecimentos marcantes, desafios, planos para o futuro, valores e crenças pessoais). 


\section{Procedimento}

Para aceder aos participantes recorreu-se ao pedido de autorização para recolha de dados à Direção Geral de Reinserção e Serviços Prisionais (DGRSP) num Centro Educativo (centro onde os menores que praticaram crimes são institucionalizados). Após esta autorização, foi obtido o consentimento informado dos jovens e/ou dos seus representantes legais, garantindo-se o anonimato dos participantes bem como a ocultação/alteração de qualquer relato que possa ser passível de identificação dos participantes. As entrevistas foram realizadas nas instalações do Centro Educativo, com uma duração média entre os 45 e os 120 minutos. As entrevistas foram gravadas e transcritas na íntegra, de modo a salvaguardar-se a integridade dos relatos para posterior análise.

\section{Metodologia de Análise}

Utilizou-se a metodologia da análise temática, sob uma perspetiva construcionista social. A análise temática foi seguida tal como indicada por Braun e Clarke (2006), adotando-se o procedimento de codificação indutiva em que os temas identificados estão fortemente ligados aos dados, não se procurando ajustar a um quadro de codificação pré-existente - data-driven. Recorremos ao software NVivolo (QSR) para o processo de organização, codificação e interpretação dos dados.

Os temas não são mutuamente exclusivos, podendo codificar-se o mesmo excerto de texto em vários temas, sendo que procedemos às seguintes etapas:

a. Em primeiro, teve lugar a fase de familiarização com os dados, na qual realizámos (re)leituras dos dados, tendo sido anotadas ideias relevantes.

b. Numa segunda etapa, construímos os códigos iniciais (elementos dos dados considerados relevantes), organizando os dados em grupos significativos.

c. Concluída esta fase, realizámos à análise dos diferentes códigos e estabelecemos a relação entre os mesmos, combinando-os para formar temas principais e subtemas, obtendo-se um mapa de temas d. Numa quarta etapa, procedeu-se à revisão de todos os dados codificados, fazendo leituras sistemáticas dos excertos de texto recolhidos para cada tema, analisando se os temas formavam um padrão coerente.

e. Por último, redefinimos os temas iniciais, gerando definições claras e nomes para cada tema/ subtema, sendo essas designações concisas de modo a proporcionar sentido ao que abordam.

A validação dos resultados constituiu uma outra etapa, no sentido de se assegurar a confiança e credibilidade dos resultados, destacando-se, em particular, o recurso a um co-codificador na análise do material recolhido. $O$ co-codificador analisou cerca de $30 \%$ do material recolhido, ou seja, três entrevistas selecionadas aleatoriamente. Procedeuse ao cálculo do índice de validade conforme a fórmula apresentada por Vala (1986) $\mathrm{F}=2(\mathrm{Cl}$, 2) / $\mathrm{Cl}+\mathrm{C} 2$, dividindo o número de acordos entre codificadores pelo total de categorizações efetuadas por cada um. Obteve-se um índice de fidelidade de 0.85, considerando uma força de acordo substancial.

\section{Resultados}

Com vista a um maior entendimento do estudo em causa, a apresentação dos resultados seguirá a ordem das questões orientadoras.

Quais são os temas e experiências centrais que surgem na sua história de vida? Como são significados esses temas e/ou experiências?

Ao longo das entrevistas, emergiram cinco temas centrais do discurso dos participantes: em primeiro lugar a família, em segundo lugar o grupo de pares, seguindo-se os comportamentos delinquentes, o percurso escolar e a institucionalização/reclusão. Seguidamente, procedemos à descrição detalhada de cada um dos temas, por ordem decrescente (desde o tema mais abordado até ao menos abordado). 
Tabela 1. Principais temas relatados pelos participantes

\begin{tabular}{ccc}
\hline & Número de Participantes & Referências \\
\hline Famália & 8 & 69 \\
Grupo de & 7 & 58 \\
Pares/Relacionamentos & & \\
Comportamentos Delinquentes & 7 & 47 \\
Percurso Escolar & 4 & 29 \\
Institucionalização & 8 & 26 \\
\hline
\end{tabular}

Família

Tendo em conta a Tabela 1, é possível verificar que oito dos nove participantes integra no seu discurso a família em sentidos completamente opostos, mas alvo da mesma atenção, as vivências positivas ( 7 participantes ; 36 referências ) e as vivências negativas $(7 ; 35)$.

Relativamente às vivências positivas estas dizem respeito ao suporte familiar $(3 ; 6)$ e às relações positivas $(7 ; 30)$ que associam, principalmente, à figura materna e aos irmãos.

J1: A coisa mais importante para mim é a família.

J3: Outro ponto alto, não foi bem um ponto alto, mas foi quando tive noção do quanto gostava do meu irmão.

As vivências negativas referem-se aos maus tratos sofridos $(3 ; 8)$, ao divórcio/desintegração familiar $(6 ; 11)$ e à perda/abandono familiar $(7 ; 17)$, destacando-se as duas últimas, que revelam o impacto da desestruturação familiar na vida destes jovens

J1: Foi a separação dos meus pais, tinha 7 ou 8 anos (...) mexeu comigo, era um miúdo irritado, revoltado depois de se terem separado.

J2: O meu pai, ele nunca estava ao pé de mim.

J4: Depois a minha mãe ausentou-se, comecei a fazer asneiras e fui para uma instituição da segurança social.

\section{Grupo de pares/Relacionamentos}

No que se refere ao grupo de pares/ relacionamentos, tal como aconteceu com a família, os jovens referem experiências positivas e experiências negativas, revelando que as relações/ laços constitui uma dimensão que tem relevância na vida destes jovens, tanto no sentido positivo como negativo. No relacionamento com os pares, os participantes evidenciam principalmente o convívio/ relações positivas $(7 ; 32)$.

J7: Sei lá, a convivência com os meus amigos, que hoje ainda são meus amigos. Sei lá, fazíamos tudo juntos.

J4: ... quando eu brincava com os meus colegas a fazer cabanas, tinha 9/10 anos. Ainda me lembro deles (...) nessa altura sentia alegria.

É no âmbito das relações amorosas $(5 ; 6)$ que os jovens referem algumas experiências negativas $(2 ; 3)$ mas destacam, essencialmente, as positivas $(5 ; 23)$, que proporcionaram sensações de bem-estar.

J3: Gostei dela, da maneira dela ser, de estar, sempre bem-disposta, andar de skate. Era diferente. J7: O que é que mudou em mim? Então, sei lá, mudou quase tudo (...) foi bom tê-la conhecido.

\section{Comportamentos delinquentes}

Os comportamentos delinquentes constituem - terceiro tema mais relatado. A maioria dos jovens foca as consequências negativas destes comportamentos $(5 ; 21)$, nomeadamente sentimentos de culpa/remorsos $(4 ; 5)$, danos corporais/ agressões que sofreram $(3 ; 10)$ e o envolvimento das autoridades/privação da liberdade $(3 ; 6)$.

J2: Agora sinto remorsos, ele também não é rico, não se deve roubar ninguém, mas muito menos uma pessoa pobre que passa dificuldades.

J7: ...tive umas costelas fraturadas.

J9: Só me causou problemas com a polícia e agora estou aqui, preso.... 
Verifica-se que os comportamentos delinquentes/ desviantes surgem muito no contexto das experiências com os pares, nomeadamente o consumo de substâncias $(4 ; 9)$

J2: la com um amigo e quatro amigas para casa de outro amigo meu, íamos fumar ganza, fazíamos o marroquino, era sempre a rodar por nós (...) depois saíamos e aí já era diferente, bebíamos shots, absinto, bebidas mesmo fortes.

J8: Comecei a consumir haxixe.

Além disto, os jovens relatam também comportamentos que se constituem como crime $(5 ; 17)$, admitindo a prática de crimes contra a propriedade (4: 13)

J2: Uma vez fui passar férias com ele a França, depois quis-me vir embora e ele revistou-me a mim e às minhas malas, eu não gostei disso, então depois roubei-lhe o ouro e vi-me embora.

J9: Foi numa manhã, tinha roubado uma mochila cheia de telemóveis a uma equipa de futebol.

e a prática de crimes contra as pessoas $(3 ; 3)$

J2: Foi quando roubei o meu pai e quando bati na minha mãe.

J4: Andávamos por aí na rua, encontramos um rapaz, abordamo-lo e correu mal, dei-lhe quatro facadas, foi a coisa mais grave que fiz na vida.

Quando se referem aos comportamentos delinquentes/criminais, os jovens abordam também as suas causas $(3 ; 4)$ mas estas remetem exclusivamente para a sua desresponsabilização $(3 ; 4)$, ou seja, atribuem a responsabilidade a terceiros e/ou a fatores externos.

J9: Podem pensar que foi uma coisa má, mas quem soube o que se passou... toda a gente me diz que foi um azar que eu tive.

J8: Mas foi uma fase má da minha vida, a minha mãe também teve doente e assim, depois, sim, comecei a vender droga e vim para aqui.

\section{Percurso Escolar}

O percurso escolar é outro dos temas abordados, referindo-se maioritariamente ao absentismo escolar/mau comportamento $(4 ; 22)$, comparativamente ao percurso académico adaptativo $(4 ; 7)$. O percurso académico adaptativo, tal como o nome indica, diz respeito a um processo de integração e aprendizagem normativo/sem questões problemáticas.

J8: Depois entrei para o $1^{\circ}$ ano, fiz a escola primária, correu bem.

É de destacar que o absentismo escolar/mau comportamento surge associado às consequências e/ou do início dos comportamentos delinquentes.

J1: Preferia andar na rua com os meus amigos. Não gostava das aulas, fazia palhaçadas e portava-me mal.

J7: Sei lá, o que é que eu fazia... então faltava à escola e ia cometer crimes.

Institucionalização/reclusão

A institucionalização/reclusão é outro tema central, despoletando nos jovens experiências ambíguas. Por um lado, exclusivamente os jovens que possuem uma história de institucionalização na infância caracterizam-na como um processo difícil e que despoleta sentimentos de revolta $(4 ; 7)$. Por outro, principalmente os jovens que só foram institucionalizados na sequência do crime, percepcionam a institucionalização no centro educativo como uma mudança positiva $(4 ; 6)$.

Relativamente à revolta/processo difícil, os jovens verbalizam a dificuldade na aceitação e permanência na instituição de acolhimento

19: Como é que eu lidei, é difícil, mas ainda agora fogo... é difícil lidar com isto, ficar trancado cá dentro, sem ir à rua.

J3: Senti raiva, senti que queria estar com a minha mãe o mais que tudo.

No entanto, os participantes reconhecem o papel da institucionalização na sua mudança como sendo uma oportunidade para recomeçar e amadurecer

J8: Um recomeço, porque eu, sei lá, isto não... eu não levo isto como algo mau que me aconteceu (...) 
mas agora... não vou dizer "ai isto é melhor do que "tar em casa", mas isto é bom p'ra mim, é outro modo de vida aqui.

J2: O ponto alto agora é ter crescido, ter maturidade. Aconteceu quando entrei aqui no centro.

Além disto, os jovens referem as transferências constantes de instituição $(4 ; 6)$, relatando a instabilidade que resulta das trocas frequentes de instituição

J2: Estava sempre a trocar de lugar, onde vivia, não sabia bem onde estava, estava numa instituição depois ia para outra.

J4: Comecei a fazer asneiras e fui para uma instituição da segurança social, uma instituição temporária, depois fui para outra instituição, e como me estava a portar mal nessa fui para outra em Castelo Branco, depois vim parar aqui.

Por fim, os jovens abordam também os motivos da sua institucionalização na infância $(3 ; 5)$ que, maioritariamente, associam à perda/abandono e/ ou aos maus-tratos perpetrados pela família

19: A minha mãe andava sempre a bater-me. Um dia ameaçou-me com uma faca. E eu comecei a andar sempre na rua. Foi por isso que fui parar à instituição..

J2: Estava sempre a trocar de instituição devido a agressões na minha casa e depois em casa dos meus avós.

\section{A delinquência ou os comportamentos antissociais é um tema que surge na sua história de vida? Se sim, que tipos de comportamentos delinquentes são relatados? De que forma? Como os significam?}

Tal como já foi referido, os comportamentos antissociais/delinquentes são, de facto, um dos temas predominantes no discurso dos jovens. Esses comportamentos traduzem-se, na maior parte dos casos, em experiências que partilham com os pares (7:21), nomeadamente o consumo de substâncias associados à integração no grupo e/ou descontração/desinibição.

J7: Comecei a entrar num mau ambiente, comecei a consumir haxixe.
J2: Sentia muita adrenalina, ria-me muito, sentia-me descontraído.

Quanto à prática de crimes contra a propriedade, relatam especificamente furtos

J4: Quando tinha 12 anos, eu e uns amigos roubámos um mp3 no continente.

J7: Os mais velhos do meu bairro roubavam os carros e depois eu ia lá e roubava os carros.

Os crimes contra as pessoas são descritos como tendo sido praticados em grupo, mas ao nível individual são perpetrados contra familiares.

J4: Andávamos por aí na rua, encontramos um rapaz, abordamo-lo e correu mal, dei-lhe quatro facadas.

J2: O outro momento baixo foi quando bati na minha mãe.

É de referir que as consequências dos comportamentos delinquentes são avaliadas como negativas, quer pelos danos corporais ou agressões que também sofreram decorrentes desses comportamentos, como também pelos sentimentos de culpa/remorsos que despoletaram nos jovens.

J4: Nessa altura não sabia o que fazer, não pensava que eu tinha ferido o rapaz, só quando a polícia nos apanhou e nos disse que o rapaz estava no hospital é que eu percebi a gravidade da situação.

J9: $O$ segurança estava-me a agarrar e de repente, caiu no chão... fogo, foi mesmo... nos primeiros meses que tive aqui senti muitos remorsos sobre isso, dormia mal e tudo fogo, pensava muito nisso.

Que experiências ou situações são consideradas, implícita ou explicitamente, na forma como se percepcionam a si próprios e ao seu percurso de vida (passado, presente e futuro)?

Os participantes verbalizam diversas situações/ experiências onde é patente $o$ impacto que estas exercem na percepção que têm de si e do seu percurso de vida. Os jovens quando fazem uma autoanálise e se definem em função daquilo que viveram/experienciaram revelam aspetos identitários $(8 ; 90)$ quer negativos $(7 ; 55)$, como positivos $(7 ; 34)$. 
Os aspectos negativos sobrepõem-se aos positivos, destacando-se a impulsividade/rebeldia/ inconsequência $(6 ; 20)$

J7: Eu não pensava nas consequências

J4: Da minha maneira de ser este momento diz-me que eu às vezes ajo sem pensar.

Segue-se $\circ$ arrependimento/fracassos/culpa $(5 ; 16)$, sobretudo fracasso ao nível das relações familiares e/ou amorosas.

J3: Desiludir a minha mãe

J2: Considero isto um fracasso porque sei que ela era uma miúda diferente, diferente das outras, não encontro miúdas iguais a ela, podia ter lutado por ela.

Por fim, destaca-se também a revolta e o impacto dos maus-tratos $(3 ; 17)$, nomeadamente sentimentos de revolta face aos maus-tratos sofridos na família.

J1: Se não tivesse este momento na minha vida, a minha vida seria diferente e melhor, sem esta fase se calhar não estava aqui, porque eu estava muito revoltado.

J2: Raiva, porque ela levantou-me a mão como fazia antigamente, senti revolta, estava muito revoltado.

No entanto, apesar de diminutos, emergem também aspectos identitários positivos, nomeadamente, - crescimento/maturidade/mudança (7;17), as capacidades pessoais/resiliência $(4 ; 9)$ e os sentimentos de autoeficácia e prazer nas atividades de lazer/hobbies $(2 ; 10)$.

O crescimento/maturidade/mudança positiva é reportado pelos participantes como resultado da institucionalização, apesar das dificuldades.

J2: O ponto alto agora é ter crescido, ter maturidade. Aconteceu quando entrei no centro.

$\mathrm{J} 1$ : Mudou um bocado a minha forma de ser.

Além disso, emerge do discurso dos participantes as suas capacidades pessoais/resiliência.

J2: Sou sentimental.

J3: Que me adapto bem.
Por fim, os participantes relatam $\circ$ prazer nas atividades de lazer/hobbies que contribuem para $\circ$ aumento da sua autoestima e integração no grupo de pares

J4: Eu gosto de ir muito a festas (...) gosto de sair à noite, gosto de ir a festas.

J3: Adoro e sinto-me bem a andar de skate.

Tal como referido anteriormente, a família surge como o tema primordial no discurso dos jovens, seguindo-se o grupo de pares. Isto verifica-se mais uma vez, quando todos os participantes referem $\circ$ valor e o apreço que têm pela família e amigos, acima de todas as coisas

J7: Minha família, porque são as pessoas mais importantes p'ra mim. A seguir, os meus amigos.

J8: $O$ que é que eu mais defendo? A minha família. e o quanto valorizam a união familiar mesmo após experiências negativas/adversas.

J1: Com este momento acho que aprendi muitas coisas, se eu tiver um filho não me vou separar da minha mulher, aprendi a valorizar a união da família.

J5: O nome do primeiro capitulo seria dor, porque estava praticamente longe da minha família.

Ao nível da projeção no futuro, os participantes consideram sobretudo a família e os comportamentos delinquentes (na tentativa de recuperar o tempo e a "vida" perdida), quando expressam a vontade de ter uma profissão/arranjar trabalho $(9 ; 20)$ ou de terminar os estudos $(6 ; 11)$.

J1: Sonho ser futebolista e vou trabalhar para isso. J3: Sair daqui, terminar os estudos, tirar o curso de hotelaria.

No entanto, quer a intenção de arranjar trabalho quer a intenção de terminar os estudos está intimamente ligada com o desejo de ajudar/ recompensar a família $(7 ; 10)$ pelos danos causados

J9: Vou ajudar a minha família, vou ajudar a minha mãe, os meus irmãos" ou de formar família

J2: Ter uma mulher que gostasse mesmo de mim e construir uma família. 
Os jovens consideram também explicitamente os comportamentos delinquentes quando relatam a intenção de sair do centro educativo e não reincidir.

J3: Quero mais é sair daqui.

J9: É a minha saída, não ter mais envolvimentos com o tribunal.

\section{Discussão}

Da análise dos resultados, verifica-se que parece existir um discurso consensual na história de vida destes jovens. A maioria dos participantes falam-nos das mesmas questões em relação aos comportamentos delinquentes, ao percurso escolar, à institucionalização e à projeção no futuro, no entanto são as relações, quer com a família, quer com o grupo de pares, que assumem maior destaque.

A relação/identificação da família é ambivalente, uma vez que esta é significado de amor, união, proteção e segurança e, ao mesmo tempo, significado de desproteção, de ausência de amor e afeto, de instabilidade, mágoa, abandono e ressentimento. Segundo Levisky (2002) a rejeição por parte da sociedade, mas sobretudo por parte dos pais e da família, exerce impacto ao nível da construção da identidade, podendo diminuir o autoconceito positivo e a autoestima. A literatura indica que as crianças que sofreram algum tipo de violência intrafamiliar apresentaram mais problemas de comportamento ou sintomas depressivos na adolescência (Estevam, 2011 ; Wathier \& Dell'Aglio, 2007). Porém, apesar dos nossos jovens apresentarem esta ambivalência, a família assume imensa importância/valorização, quer quando fazem uma retrospetiva da sua vida, como quando se projetam no futuro.

grupo de pares exerce também um papel crucial na vida destes jovens, podendo funcionar como um recurso compensatório face às experiências de abandono, maus-tratos ou sentimentos de rejeição no contexto familiar. $O$ grupo de pares surge essencialmente como sinónimo de partilha, de compreensão, de companheirismo, de troca de experiências e igualdade, mesmo quando ocorrem comportamentos delinquentes. Assim, à semelhança do que a literatura indica, a associação a grupo de pares desviantes parece facilitar o envolvimento em comportamentos delinquentes (Boakye, 2012).

No que se refere aos comportamentos delinquentes, os jovens apresentam um padrão comum: o cometimento de vários tipos de crime (tanto contra a propriedade, como contra as pessoas), cometidos individualmente no contexto intrafamiliar e em grupo no contexto extra-familiar. Todos os jovens se desresponsabilizam pelas práticas criminais, atribuindo-as a fatores externos (e.g.: sorte vs. azar). Paradoxalmente, são notórios os sentimentos de culpa e os remorsos. Como refere Laranjeira (2007) as infrações podem ser uma forma dos jovens controlarem a sua desordem interior ou surgirem da necessidade de se afirmarem e obterem alguma autonomia. No presente estudo, os jovens apresentam dificuldades na gestão e integração emocional das experiências de maus tratos, abandono e instabilidade, podendo recorrer aos comportamentos desviantes como forma de conseguir algum controlo sobre a sua vida e experiência emocional.

Relativamente ao percurso escolar dos jovens, este caracteriza-se maioritariamente pelo absentismo que, como vimos, muitas vezes é o primeiro passo para as práticas criminais, não se identificando com a escola. Este dado vai ao encontro de outros estudos, que indicam que a escola parece estar afastada dos jovens delinquentes (Simões et al., 2008) e que, pelo absentismo, estes acabam por ter mais tempo disponível para se envolverem em comportamentos delinquentes (Boakye, 2012 ; Donges, 2015).

Também os discursos relacionados com a institucionalização são consensuais entre os participantes. Destes emergem as referências aos sentimentos de revolta por serem retirados da sua família, da sua casa e do seu ambiente, assim como os sentimentos de tristeza e ressentimento pelo motivo da institucionalização na infância (maioritariamente associado com a perda/abandono e/ou maustratos perpetrados pela família), mas também da instabilidade recorrente das transferências constantes, dificultando o processo de integração e promovendo a confusão e a desorientação. Neste sentido, realça-se a necessidade dos jovens serem alvo de políticas de proteção que assegurem um desenvolvimento saudável (Costa \& Assis, 2006). 
Em relação ao futuro, todos se projetam de forma optimista, verbalizando a intenção de concluir os estudos, de obter uma profissão, de ajudar e/ou formar uma família e de não reincidir. Estes dados vão ao encontro de alguns estudos (e.g. Estevam, 2011) que indicam que quando questionados sobre o futuro, referem querer sair da situação em que estão, conseguir liberdade, estudar, trabalhar, mudar de vida, ter uma profissão e formar uma família. Isto revela a importância de delinear com os jovens um projeto de vida, sendo essencial pegar nos seus desejos e aspirações para reconstruir uma nova história, uma história alternativa à história delinquente. a delinquência e um contexto de desenvolvimento de competências (Estevam, 2011). Os nossos jovens revelaram a privação de experiências escolares positivas e de sucesso, o que parece ter facilitado a sua desintegração do contexto escolar e o seu envolvimento em actividades/práticas desviantes (Boakye, 2012; Simões et al., 2008).

\section{Conflitos de interesses}

Nenhum conflito financeiro, legal ou político envolvendo terceiros (governo, empresas e fundações privadas, etc.) foi declarado para nenhum aspecto do trabalho submetido (incluindo mas não limitandose a subvenções e financiamentos, conselho consultivo, desenho de estudo, preparação de manuscrito, análise estatística, etc).

\section{Considerações finais}

O presente estudo mostra a importância de desenvolver estudos qualitativos sobre a delinquência, isto é, estudos que procurem compreender a delinquência para além da sua prevalência, da sua caracterização e dos seus factores de risco ou protetores. Não podemos ignorar que os comportamentos delinquentes não podem ser compreendidos sem se considerar o seu contexto e que os próprios fatores de risco e/ ou protetores assentam numa rede complexa de múltiplas combinações ao longo da vida que podem sustentar e ou inibir trajetórias delinquentes.

Através da identificação das experiências e dos significados atribuídos, o trabalho desenvolvido com os jovens será facilitado, quer ao nível da (re) significação positiva/alternativa, quer ao nível da exploração e utilização do potencial de cada um, colocando de parte assunções estigmatizantes como "jovem delinquente" que descartam a possibilidade de existência como jovem "comum" ou não delinquente, dotado das mesmas oportunidades que os de mais. Por fim, há a destacar que o relato dos jovens indica pontos de intervenção a considerar na sua reintegração social, nomeadamente o foco no planeamento e prossecução de um projeto de vida (a nível escolar e profissional), bem como o investimento em relações positivas e adequadas com a família e pares significativos não desviantes. É de realçar também a importância de intervir ao nível escolar, dado que a escola pode ser um fator protetor para

\section{Referências}

Agan, M. L. F., Costin, A. S., Deutz, M. H. F., Edelsbrunner, P. A., Zális, L., \& Franken, A. (2015). Associations between risk behaviour and social status in European adolescents. European Journal of Developmental Psychology, 12(2), 189-203. Recuperado de http:// www.tandfonline.com/doi/abs/10.1080/17405629.2 014.975790. doi: $10.1080 / 17405629.2014 .975790$

Boakye, A. O. (2012). Juvenile Delinquency in Ghana: A Qualitative Study of the Lived Experiences of Young Offenders in Accra. Recuperado de https://brage.bibsys.no/xmlui/bitstream/ handle/ 1 1250/270842/535610_FULLTEXT01. pdf? sequence $=1$

Braga, T., \& Gonçalves, R. J. A. C. (2013). Delinquência juvenil: Da caracterização à intervenção. Revista de Psicologia da Criança e do Adolescente, 4(1), 95-1 16. Recuperado de http://revistas.lis.ulusiada.pt/index. $\mathrm{php} / \mathrm{rpca} /$ article/view/93/88

Braun, V., \& Clarke, V. (2006). Using thematic analysis in psychology. Qualitative Research in Psychology, 3(2), 77-101. Recuperado de http://eprints.uwe. ac.uk/1 1735. doi: $10.1191 / 1478088706$ ap063oa

Burfeind, J.W., \& Bartusch, D.J. (2011). Juvenile delinquency: An integrated approach. Sudbury, MA: Jones and Bartlett.

Carvalho, M. J. L., \& Duarte, V. M. (2013). Crianças, Jovens e a Cidade: riscos, violências e delinquências em Portugal. Latitude, 7(2), 133-166. Recuperado de http://www.seer.ufal.br/index.php/latitude/article/ view/1292/893 
Conde, R., \& Paiva, B. (2014). Entrevista sobre a história de vida para Jovens, versão para investigação. Porto: Universidade Lusófona do Porto.

Conde, R., \& Teixeira, S. (2017). Histórias de vida de jovens delinquentes: $O$ contributo da investigação qualitativa para a compreensão da delinquência juvenil. Atas CIAIQ2017: Investigação Qualitativa em Ciências Sociais. Salamanca, Espanha, 3. Recuperado de http://proceedings.ciaiq.org/index.php/ciaiq2017/ article/view/1445/1402

Costa, C.R.B.S.F., \& Assis, S. G. (2006). Fatores protetivos a adolescentes em conflito com a lei no contexto socioeducativo. Psicologia \& Sociedade, 18(3), 74-81. Recuperado de http://www.scielo.br/pdf/ psoc/v18n3/a 11 v18n3.pdf. doi: 10.1590/S010271822006000300011

Duarte, V. (2012). Contextos, discursos e percursos na delinquência juvenil feminina. Configurações. Revista de sociologia, 9, 121-133. Recuperado de http:// journals.openedition.org/configuracoes/ 1148

Donges, W. E. (2015). A qualitative case study: lived educational experiences of former juvenile delinquents. The Qualitative Report, 20(7), 10091028. Recuperado de http://nsuworks.nova.edu/tqr/ vol20/iss7/6

Estevam, I. D. (2011). Adolescente em conflito com a lei, resiliência, valores humanos e suporte familiar: um estudo das representações sociais (Tese de Doutorado). Universidade Federal do Paraíba/ Universidade Federal do Rio Grande do Norte, João Pessoa, PB, Brasil.

Guimarães, J. V. C. (2012). Autoconceito, autoestima e comportamentos desviantes em adolescentes (Dissertação de Mestrado). ISPA-Instituto Universitário, Lisboa, Portugal.

Sander, B. S., Sharkey, J. D., Olivarri, R., Tanigawa, D. A., \& Mauseth, T. (2010). A Qualitative Study of Juvenile Offenders, Student Engagement, and Interpersonal Relationships: Implications for Research Directions and Preventionist Approaches. Journal of Educational and Psychological Consultation, 20(4): 288-315. Recuperado de http://www.tandfonline.com/doi/ abs/10.1080/10474412.2010.522878. doi: $10.1080 / 10474412.2010 .522878$

Kagan, J. (2004). Reappraising T.L:O.'s "Special Needs" Doctrine in an Era of School-Law Enforcement Entanglement. Journal of Law \& Education, 33(3), 291-325.
Laranjeira, C. A. (2007). A análise psicossocial do jovem delinquente: uma revisão da literatura. Psicologia em estudo, 12(2), $221-227$. Recuperado de http:// www.scielo.br/pdf/pe/v12n2/v12n2a02.pdf. doi: $10.1590 /$ S $1413-73722007000200002$

Levisky, D. L. (2002). Construção da identidade, o processo educacional e a violência - uma visão psicanalítica. Pro-posições, 13(3), 99-112. Recuperado de https:// periodicos.sbu.unicamp.br/ojs/index.php/proposic/ article/view/8643939/11395

López, E. E., Pérez, S. M., Ochoa, G. M., \& Ruiz, D. M. (2008). Adolescent aggression: Effects of gender and family and school environments. Journal of Adolescence, 31 (4), 433-450. Recuperado de https://www.ncbi. nlm.nih.gov/pubmed/18023860. doi: 10.1016/i. adolescence.2007.09.007

McAdams, D.P. (2008). The Life Story Interview. Recuperado de www.sesp.northwestern.edu/docs/ LifeStorylnterview.pdf

Ministério da Administração Interna (2014). Relatório Anual de Segurança Interna 2014. Recuperado de http:// www.parlamento.pt/Documents/XIILEG/Abril_2015/ relatorioseginterna2014.pdf

Morizot, J. \& Kazemian, L. (2015). The development of criminal and antisocial behavior. Switzerland: Springer.

Nardi, F. L., \& Dell'aglio, D. D. (2010). Delinquência juvenil: uma revisão teórica. Acta Colombiana de Psicología, 13(2), 69-77. Recuperado de http://www.scielo.org. $\mathrm{co} / \mathrm{pdf} / \mathrm{acp} / \mathrm{v} 13 \mathrm{n} 2 / \mathrm{v} 13 \mathrm{n} 2 \mathrm{a} 07 . \mathrm{pdf}$

Sander, J. B., Sharkey. J. D., Olivarri, R., Tanigawa, D. A., \& Mauseth, T. (2010). A Qualitative Study of Juvenile Offenders, Student Engagement, and Interpersonal Relationships: Implications for Research Directions and Preventionist Approaches. Journal of Educational and Psychological Consultation, 20(4), 288-315. Recuperado de http://www.tandfonline.com/doi/ abs/10.1080/10474412.2010.522878. doi: $10.1080 / 10474412.2010 .522878$

Simões, C., Matos, M.G., \& Batista-Foguet, J. M. (2008). Juvenile delinquency: analysis of risk and protective factors using quantitative and qualitative methods. Cognition, Brain, Behavior. An Interdisciplinary Journal, 4(XII), 389-408. Recuperado de http://www.ascred. ro/images/attach/Juvenile $\% 20$ deliquency $\% 20$ analysis $\% 20$ of $\% 20$ risk $\% 20$ and $\% 20$ protective $\% 20$ factors $\% 20$ using $\% 20$ quantitative $\% 20$ and $\% 20$ qualitative $\% 20$ methods.pdf 
Thijs, P. E., van Dijk, I. K., Stoof, R., \& Notten, N.

(2015). Adolescent problem behaviour: The gender gap in European perspective. European Journal of Criminology, 12 (5), 598-615.

Recuperado de http://journals.sagepub.com/ doi/pdf/10.1177/1477370815578195. doi: $10.1177 / 1477370815578195$

Vala, J. (1986). A análise de Conteúdo. In Silva, A. S., \& Pinto, J. M. (Orgs.), Metodologia das Ciências Sociais (pp. 101-128). Porto: Afrontamento.

Vieira, S. M. N. (2014). Representações sociais sobre a delinquência juvenil: estudo comparativo entre duas amostras de estudantes pós-graduados (Dissertação de mestrado). Instituto Superior de Ciências Sociais e Políticas, Universidade de Lisboa, Lisboa, Portugal.

Wathier, J. L., \& Dell'Aglio, D. D. (2007). Sintomas depressivos e eventos estressores em crianças e adolescentes no contexto de institucionalização. Revista de Psiquiatria do Rio Grande do Sul, 29(3), 305-314. Recuperado de http://www.scielo.br/pdf/rprs/v29n3/v29n3a10. pdf. doi: $10.1590 /$ S0101-81082007000300010 